\title{
Ocular Manifestations of Acquired Immunodeficiency Syndrome
}

\author{
Young Shin Kim ${ }^{1}$, Hae Jung Sun ${ }^{1}$, Tae Hyong Kim², Kui Dong Kang ${ }^{3}$, Sung Jin Lee ${ }^{1}$ \\ ${ }^{I}$ Department of Ophthalmology, Soonchunhyang University Seoul Hospital, Soonchunhyang University College of Medicine, Seoul, Korea \\ ${ }^{2}$ Department of Internal Medicine, Soonchunhyang University Seoul Hospital, Soonchunhyang University College of Medicine, Seoul, Korea \\ ${ }^{3}$ Department of Ophthalmology, Incheon St. Mary's Hospital, The Catholic University of Korea College of Medicine, Incheon, Korea
}

Purpose: To investigate the patterns and risk factors of the ocular manifestations of acquired immunodeficiency syndrome (AIDS) and their correlation with CD4+ count in the era of highly active antiretroviral therapy (HAART).

Methods: This retrospective study examined 127 AIDS patients who presented to Soonchunhyang University Hospital. Data were collected from patient interviews, clinical examinations, and laboratory investigations. Ophthalmologic examinations included the best-corrected visual acuity, intraocular pressure, anterior segment and adnexal examination, and dilated fundus examination.

Results: Of the 127 patients with AIDS, 118 were on HAART and 9 were not. The mean CD4+ count was 266.7 \pm 209.1 cells/ $/ \mathrm{L}$. There were ocular manifestations in 61 patients $(48.0 \%)$. The incidence of anterior segment manifestations was higher than posterior segment manifestations at $28.3 \%$ and $19.7 \%$, respectively. The mean CD4+ count was significantly $(p<0.05)$ lower in the patients with posterior versus anterior segment ocular manifestations. The most common ocular manifestation was retinal microvasculopathy $(15.0 \%)$, followed by keratoconjunctivitis sicca $(14.2 \%)$, conjunctival microvasculopathy $(9.4 \%)$, cytomegalovirus retinitis $(3.1 \%)$, herpes zoster ophthalmicus (2.4\%), and blepharitis (1.6\%). Retinal microvasculopathy and cytomegalovirus retinitis were common in patients with CD4+ counts $<200$ cells $/ \mu \mathrm{L}$, while keratoconjunctivitis sicca and conjunctival microvasculopathy were common in patients with CD4+ counts of 200 to 499 cells/ $\mu \mathrm{L}$. There was a significant $(p<0.05)$ association between ocular manifestation and CD4+ count or age.

Conclusions: The introduction of HAART has changed the landscape of ocular presentations in patients with AIDS. In this study, anterior segment and external ocular manifestations occurred more frequently than posterior segment manifestations. Also, the mean CD4+ count was significantly lower in patients with posterior segment ocular manifestations versus anterior segment ocular manifestations. We found that CD4+ count and age $>35$ years were independent risk factors for developing ocular manifestations.

Key Words: Acquired immunodeficiency syndrome, CD4-positive T-lymphocytes, Eye manifestations, Highly active antiretroviral therapy

Received: August 22, 2014 Accepted: February 26, 2015

Corresponding Author: Sung Jin Lee, MD, PhD. Department of Ophthalmology, Soonchunhyang University Seoul Hospital, \#59 Daesagwan-ro, Yongsan-gu, Seoul 140-743, Korea. Tel: 82-2-709-9354, Fax: 82-2-7103196, E-mail:wismile@schmc.ac.kr
Since the human immunodeficiency virus (HIV)/acquired immunodeficiency syndrome (AIDS) epidemic began in 1981 [1], ocular involvement has been a common finding [2-4], and loss of vision is a serious problem in people living with HIV [5]. Before the era of highly active antiretroviral therapy (HAART), ocular involvement was 
estimated to develop in $50 \%$ to $75 \%$ of patients with HIV infection [6,7], including retinal microvasculopathy, vascular occlusions, opportunistic infections such as cytomegalovirus (CMV) retinitis, and progressive outer retinal necrosis [8]. A variety of other important AIDS-related manifestations involve the anterior segment, ocular surface, and adnexae [9].

The success of HAART in restoring CD4+ T-cell immunity has significantly affected the pattern and natural history of ocular manifestations of HIV infection [10]. The overall incidence of ocular manifestations of HIV infection in people living with HIV/AIDS has decreased to less than $40 \%$. In the HAART era, there has been an estimated $80 \%$ decrease in the incidence of CMV retinitis [11]. With HAART, there have been improvements in the length [12] and quality of life of individuals with HIV. The incidence of sight-threatening complications has decreased, but attention should be still paid to other minor problems requiring ophthalmic care, including anterior segment and external ocular manifestations, which can affect the quality of life [2].

Therefore, this study describes the patterns and risk factors of the ocular manifestations of AIDS in the HAART era and their correlation to the CD4+ count.

\section{Materials and Methods}

A retrospective chart review was performed on patients seen at Soonchunhyang University Hospital from August 2004 to April 2014. Of 417 total HIV/AIDS patients, 127 were referred to the department of ophthalmology for an evaluation of ocular manifestations. Of these 127 patients, 118 were on HAART and 9 were not. Patients with additional medical problems such as diabetes mellitus, hypertension, and ocular trauma, which can have manifestations overlapping with AIDS, were excluded from the study.

Data were collected from patient interviews, clinical examinations, and laboratory investigations. Ophthalmologic examinations included the best-corrected visual acuity, intraocular pressure, anterior segment and adnexal examination, and dilated fundus examination.

Keratoconjunctivitis sicca was diagnosed using the Ocular Surface Disease Index (OSDI) questionnaire, which includes the following three domains: ocular symptoms, vision-related function, and environmental triggers [13].
Based on their OSDI scores, patients were categorized into two groups: those with a normal ocular surface (0 to 12 points) or those with ocular surface disease ( $\geq 13$ points) [14]. Conjunctival microvasculopathy was diagnosed when patients presented with microaneurysms, segmental dilation of the venules, and adjacent narrowing of the arterioles, particularly with involvement of the inferior perilimbal bulbar conjunctiva [15].

Retinal microvasculopathy was diagnosed based on the following clinical manifestations: cotton-wool spots, microaneurysms, retinal hemorrhages, telangiectatic vascular changes, and the presence of capillary non-perfusion [16]. The diagnosis of CMV retinitis was based on clinical signs and symptoms [17-20]. CMV's characteristic retinal lesion has a dry appearing granular border surrounding an area of retinal edema and full-thickness retinal necrosis (Fig. 1).

The data were analyzed using IBM SPSS ver. 21 (IBM Corp., Armonk, NY, USA). Chi-square tests were used and $p<0.05$ was considered significant. Student's $t$-tests, Fisher's exact tests, and multiple logistic regression were used to examine the associations and differences between the variables.

The study followed the tenets of the Declaration of Helsinki and was approved by the Ethics Committee of Soonchunhyang University.

\section{Results}

Of the 417 subjects with AIDS, 127 patients were assessed. The majority of patients $(96.1 \%)$ were male. The mean age of the patients was 38.7 (range, 19 to 76 ) years, and $36.9 \%$ of the patients were 30 to 39 years old. Of the
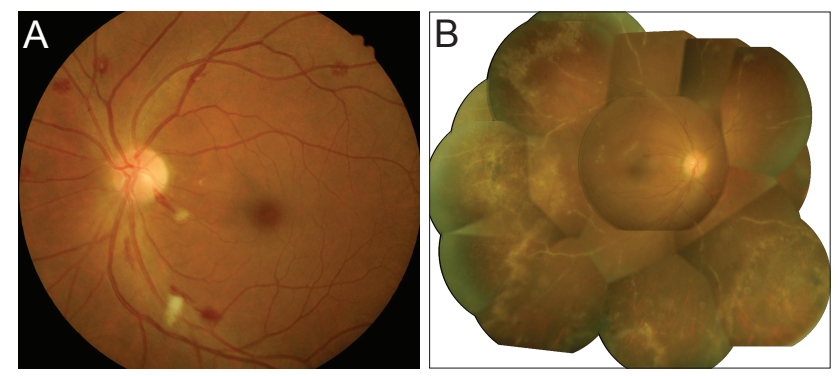

Fig. 1. (A) Fundus photograph showing retinal microvasculopathy with numerous cotton-wool spots and retinal hemorrhages. (B) Fundus photograph showing characteristic findings of cytomegalovirus retinitis, including prominent perivascular sheating and retinal necrosis with irregular granular borders. 
127 patients being assessed, 118 were on HAART and 9 were not. The mean CD4+ count was $266.7 \pm 209.1$ cells/ $\mu \mathrm{L}$. The route of HIV infection was documented in 56 patients $(44.1 \%)$ with the most common route being homosexual contact in 40 patients $(71.4 \%)$, followed by heterosexual contact in 15 (26.8\%). One patient was suspected to have been infected via blood transfusion.

Of the 127 AIDS patients, 61 (48.0\%) had ocular manifestations. The incidence of ocular manifestation in males $(47.5 \%)$ was lower than in females $(60.0 \%)$, but this difference was not significant $(p=0.585)$. The mean age of the patients with and without ocular manifestation was $40.1 \pm$ 10.8 and $37.3 \pm 12.6$ years, respectively $(p=0.172)$. Ocular manifestations were most common in the 30 to 39 years age group (36.9\%), followed by 40 to 49 years $(24.6 \%)$, and 20 to 29 years $(20.0 \%)$. However, the differences in the distribution of ocular manifestation between the age groups were not significant $(p=0.240)$. Patients with ocular manifestations had lower CD4+ counts than patients without ocular manifestations ( 233.4 vs. 297.4 cells $/ \mu \mathrm{L}$, respectively), but this difference was not significant ( $p=0.084$ ) (Table 1).

The incidence of anterior segment manifestations was higher than posterior segment manifestations, at $28.3 \%$

Table 1. Demographic characteristics and ocular manifestations of human immunodeficiency virus-infected or acquired immunodeficiency syndrome patients

\begin{tabular}{lccc}
\hline $\begin{array}{l}\text { Demographic } \\
\text { characteristics }\end{array}$ & $\begin{array}{c}\text { Ocular } \\
\text { manifestations }\end{array}$ & $\begin{array}{c}\text { No ocular } \\
\text { manifestations }\end{array}$ & $p$-value \\
\hline $\begin{array}{l}\text { Sex (male / female, } \\
\% \text { male) }\end{array}$ & $\begin{array}{c}58 / 3 \\
(95.1)\end{array}$ & $\begin{array}{c}64 / 2 \\
(97.0)\end{array}$ & $0.585^{*}$ \\
$\begin{array}{c}\text { Age (yr, range) } \\
40.1 \pm 10.8 \\
(22-68)\end{array}$ & $\begin{array}{c}37.3 \pm 12.6 \\
(19-77)\end{array}$ & $0.172^{\dagger}$ \\
Age group (yr) & & & $0.240^{\ddagger}$ \\
$10-19$ & $0(0.0)$ & $1(1.5)$ & \\
$20-29$ & $12(19.6)$ & $19(28.8)$ & \\
$30-39$ & $22(36.1)$ & $24(36.4)$ & \\
$40-49$ & $15(24.6)$ & $13(20.0)$ & \\
$50-59$ & $9(14.8)$ & $3(4.5)$ & \\
$>60$ & $3(5.0)$ & $5(8.1)$ & \\
Total & $61(48.0)$ & $66(52.0)$ & \\
CD4+ counts & $233.4 \pm 227.6$ & $297.4 \pm 186.8$ & $0.084^{\dagger}$ \\
(cells/ $\mu \mathrm{L})$ & & & \\
\hline
\end{tabular}

Values are presented as number (\%) or mean \pm standard deviation unless otherwise indicated.

${ }^{*}$ Chi-square test; ${ }^{\dagger}$ Student's $t$-test; ${ }^{*}$ Fisher's exact test. and $19.7 \%$, respectively. The mean \pm SD CD4+ count for those patients with anterior and posterior segment ocular manifestations was significantly different at $335.9 \pm 240.8$ and $85.7 \pm 80.6$, respectively $(p<0.05)$. Relative frequencies of ocular manifestations differed in patients grouped according to the CD4+ counts. Specifically, anterior segment manifestations were common in patients with CD4+ counts of 200 to 499 cells/ $\mu \mathrm{L}$ (58.3\%), while posterior segment manifestations were common in patients with $\mathrm{CD} 4+$ counts $<200$ cells $/ \mu \mathrm{L}$ (88.0\%) (Fig. 2).

Anterior segment and adnexal ocular manifestations were seen in 36 patients $(28.3 \%)$. The most common anterior segment ocular manifestation was keratoconjunctivitis sicca, which was seen in $14.2 \%$ of the patients, followed by conjunctival microvasculopathy $(9.4 \%)$ and herpes zoster ophthalmicus (2.4\%). The majority of patients with anterior segment ocular manifestations $(58.3 \%)$ had CD4+ counts of 200 to 499 cells/ $\mu \mathrm{L}$. Keratoconjunctivitis sicca and conjunctival microvasculopathy were also common in patients with $\mathrm{CD} 4+$ counts of 200 to 499 cells $/ \mu \mathrm{L}$ (Table 2).

Posterior segment ocular manifestations were seen in 25 patients (19.7\%). Retinal microvasculopathy was seen in 19 patients $(15.0 \%)$, followed by CMV retinitis (3.1\%), branch retinal vein occlusion $(0.8 \%)$, and optic neuritis $(0.8 \%)$. One patient had retinal detachment present at the time of diagnosis of CMV retinitis. Retinal microvasculopathy and CMV retinitis were common in patients with CD4+ counts $<200$ cells $/ \mu \mathrm{L}$. Other ocular manifestations, neoplasms, or opportunistic infections such as progressive outer retinal

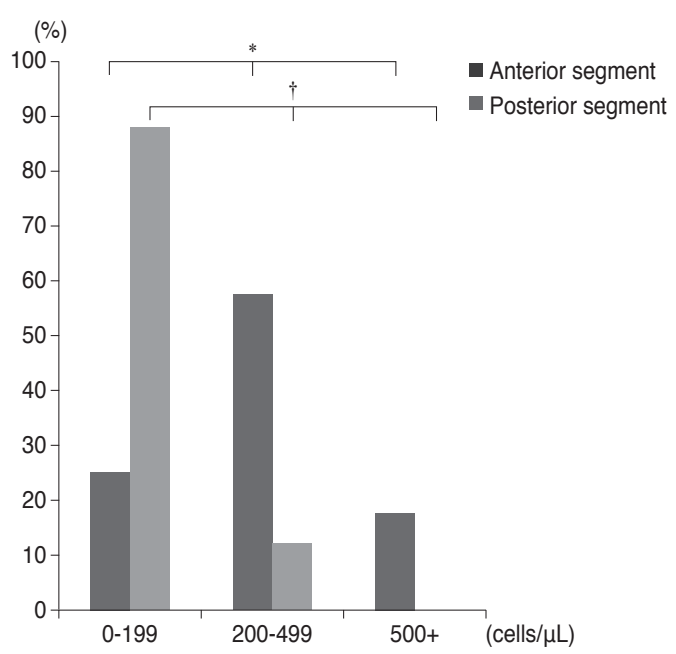

Fig. 2. Relative frequencies (percentages) of ocular manifestations in patients grouped according to the CD $4+$ counts. ${ }^{*} p<0.05$; ${ }^{\dagger} p<0.01$, chi-square test. 
Table 2. Distribution of the ocular manifestations and CD4+ counts among human immunodeficiency virus-infected or acquired immunodeficiency syndrome patients

\begin{tabular}{|c|c|c|c|c|}
\hline \multirow{2}{*}{ Ocular manifestation } & \multicolumn{3}{|c|}{ CD4+ counts $($ cells $/ \mu \mathrm{L})$} & \multirow{2}{*}{ Total } \\
\hline & 0-199 & $200-499$ & $500+$ & \\
\hline \multicolumn{5}{|l|}{ Anterior segment $^{*}$} \\
\hline Keratoconjunctivitis sicca & $4(22.2)$ & $9(50.0)$ & $5(27.8)$ & $18(14.2)$ \\
\hline Conjunctival microvasculopathy & $4(33.3)$ & $8(66.7)$ & $0(0.0)$ & $12(9.4)$ \\
\hline Herpes zoster ophthalmicus & $1(33.3)$ & $1(33.3)$ & $1(33.3)$ & $3(2.4)$ \\
\hline Blepharitis & $0(0.0)$ & $2(100.0)$ & $0(0.0)$ & $2(1.6)$ \\
\hline Uveitis & $0(0.0)$ & $1(100.0)$ & $0(0.0)$ & $1(0.8)$ \\
\hline \multicolumn{5}{|l|}{ Posterior segment } \\
\hline Retinal microvasculopathy & $18(94.7)$ & $1(5.3)$ & $0(0.0)$ & $19(15.0)$ \\
\hline Cytomegalovirus retinitis & $3(75.0)$ & $1(25.0)$ & $0(0.0)$ & $4(3.1)$ \\
\hline Branch retinal vein occlusion & $1(100.0)$ & $0(0.0)$ & $0(0.0)$ & $1(0.8)$ \\
\hline Optic neuritis & $0(0.0)$ & $1(100.0)$ & $0(0.0)$ & $1(0.8)$ \\
\hline
\end{tabular}

Values are presented as number (\%).

*Anterior segment includes adnexal and external ocular manifestations.

Table 3. Multivariate analysis of risk factors for ocular manifestations in human immunodeficiency virus-infected or acquired immunodeficiency syndrome patients

\begin{tabular}{|c|c|c|c|c|c|c|}
\hline \multirow{2}{*}{ Risk factor } & & \multicolumn{2}{|c|}{ Ocular manifestation } & \multirow{2}{*}{ Adjusted OR } & \multirow{2}{*}{$95 \% \mathrm{CI}$} & \multirow{2}{*}{$p$-value ${ }^{*}$} \\
\hline & & Yes & No & & & \\
\hline \multirow[t]{2}{*}{ Sex } & Male & $58(47.5)$ & $64(52.5)$ & 1.347 & $0.200-9.057$ & 0.759 \\
\hline & Female & $3(60.0)$ & $2(40.0)$ & & & \\
\hline \multirow[t]{2}{*}{ Age (yr) } & $>35$ & $41(57.0)$ & $31(43.1)$ & 2.177 & $1.033-4.586$ & 0.041 \\
\hline & $\leq 35$ & $20(36.4)$ & $35(63.6)$ & & & \\
\hline \multirow[t]{2}{*}{ HAART } & Yes & $58(49.2)$ & $60(50.8)$ & 1.132 & $0.458-2.796$ & 0.788 \\
\hline & No & $3(33.3)$ & $6(66.7)$ & & & \\
\hline \multirow[t]{2}{*}{ CD4+ count } & $<200$ cells $/ \mu \mathrm{L}$ & $31(59.6)$ & $21(40.4)$ & 2.228 & $1.032-4.810$ & 0.041 \\
\hline & $\geq 200$ cells $/ \mu \mathrm{L}$ & $30(40.0)$ & $45(60.0)$ & & & \\
\hline
\end{tabular}

Values are presented as number (\%); Adjusted for sex, age, CD4+ count, and HAART.

$\mathrm{OR}=$ odds ratio; $\mathrm{CI}=$ confidence interval; HAART $=$ highly active antiretroviral therapy.

"Multiple logistic regression.

necrosis were not found in this study.

Multiple logistic regression was performed using variables that were significantly associated with the presence of ocular manifestations. Patients with CD4+ counts $<200$ cells $/ \mu \mathrm{L}$ were more likely to have ocular manifestations than patients with CD4+ counts $\geq 200$ cells $/ \mu \mathrm{L}$ ( $p=0.041$; adjusted odds ratio [OR], 2.228; 95\% confidence interval [CI], 1.032 to 4.810 ). Patients $>35$ years old were more likely to have ocular manifestations than patients ageyears ( $p=$ 0.041; adjusted OR, 2.177; 95\% CI, 1.033 to 4.586). Notably, there were no significant associations between ocular manifestations and sex or HAART $(p>0.05)$ (Table 3$)$.

\section{Discussion}

The overall incidence of ocular manifestations in this study was higher than in other studies performed in Asia, which had ranged from $15.8 \%$ to $45.0 \%$ [8,21-29]. This difference is likely due to the spectrum of ocular manifesta- 
tions considered, as most articles did not include anterior segment manifestations such as keratoconjunctivitis sicca and conjunctival microvasculopathy. As the general health of individuals with HIV infection improves, the evaluation and management of disorders such as keratoconjunctivitis sicca and blepharitis, which were previously overshadowed by more severe, blinding disorders, may demand increased attention.

Keratoconjunctivitis sicca appears to be more common among individuals with AIDS (16.9\% to 38.8\%) [30-32]. Prevailing theories of its pathogenesis implicate HIV itself as the inflammatory mediator that destroys primary and accessory lacrimal glands. Direct infection and damage to the conjunctiva may also be involved [15]. Blepharitis is also common in HIV-infected individuals, and blepharitis and an eyelid ulcers have been reported to be the initial manifestations of HIV disease in some patients [33]. The pathogenesis of blepharitis in immunodeficient individuals may either involve a reduced ability to control normal flora or more complex changes in cutaneous glands of the eyelids that occur with immunosuppression [34].

The use of HAART seeks to inhibit the progression to AIDS and to prevent death by reducing plasma HIV RNA to sustained low levels, thereby bolstering immunity [35]. An enhanced immune function has been documented in the form of decreased HIV-associated opportunistic infections with associated reductions in ocular morbidity. Contrary to its effect on many other ocular HIV/AIDS-related diseases, HAART has not played a part in significantly reducing the prevalence of keratoconjunctivitis sicca. According to a recent study, $17.8 \%$ of HIV-infected individuals given HAART still presented with keratoconjunctivitis sicca after treatment [35].

With HAART, patients are less likely to be affected by blinding posterior segment infections. However, attention should be paid to minor problems requiring ophthalmic care, including anterior segment and external ocular manifestations, which can affect the quality of life [2]. In this study, the incidence of anterior segment manifestations was higher than that of posterior segment manifestations. The most common anterior segment ocular manifestation was keratoconjunctivitis sicca, followed by conjunctival microvasculopathy, comprising a significant portion of the overall incidence. The incidence of keratoconjunctivitis sicca was similar to that in other studies, $21 \%$ in the preHAART era [31] and $17.8 \%$ in the post-HAART era [35].
However, the incidence of conjunctival microvasculopathy was much lower than in studies performed in the preHAART era (75\%) [9,36-38]. Contrary to its effect on many other ocular HIV/AIDS-related diseases, HAART has not significantly reduced the incidence of keratoconjunctivitis sicca [39].

The most common ocular manifestation in this study was retinal microvasculopathy. The incidence of retinal microvasculopathy was similar to that in previous studies (8\% to $12.6 \%$ ) [8,21-29]. However, the incidence of CMV retinitis was lower than the $5.3 \%$ to $20.8 \%$ reported in other studies [8,21-29]. Before the HAART era, CMV retinitis was diagnosed in $10 \%$ to $45 \%$ of patients with late-stage AIDS, and some autopsy series documented CMV in up to $90 \%$ of patients [40-43]. By contrast, in the HAART era, there has been an estimated $80 \%$ decrease in the incidence of CMV retinitis [44]. The use of HAART has decreased plasma levels of HIV RNA and increased CD4+ counts, improving immune function of patients with HIV infection [45-47]. Immune recovery uveitis was first described in 1998 as a consequence of rapid immune reconstitution after the use of HAART in HIV patients [48]. It is characterized by the development of intraocular inflammation, cystoid macular edema, epiretinal membrane, and vitritis. However, there were no cases of immune recovery uveitis in our series.

In this study, the mean CD4+ count was significantly lower in patients with posterior segment ocular manifestations compared to anterior segment ocular manifestations. Posterior segment ocular manifestations were common in patients with $\mathrm{CD} 4+$ counts $<200$ cells $/ \mu \mathrm{L}$. It is known that the prevalence of retinal microvasculopathy is inversely proportional to the $\mathrm{CD} 4+$ count, and $\mathrm{CMV}$ retinitis is common in patients whose $\mathrm{CD} 4+$ counts are $<50$ cells $/ \mu \mathrm{L}$ [49]. However, anterior segment manifestations were common in patients with CD4+ counts of 200 to 499 cells $/ \mu \mathrm{L}$. Keratoconjunctivitis sicca is not related to the CD4+ count or associated with the severity of HIV [50]. Conjunctival microvasculopathy was also common in patients with CD4+ counts $<100$ cells/ $\mu \mathrm{L}$ [51]. Conversely, no correlation between $\mathrm{CD} 4+$ count and conjunctival microvasculopathy has been reported [52]. In this study, both keratoconjunctivitis sicca and conjunctival microvasculopathy were common in patients with CD4+ counts of 200 to 499 cells $/ \mu \mathrm{L}$.

In this study, CD4+ counts $<200$ cells $/ \mu \mathrm{L}$ and age $>35$ years were independent risk factors for developing ocular 
manifestations, with CD4+ counts $<200$ cells/ $\mu \mathrm{L}$ being a well-established risk factor [53]. Age $>35$ years was found to be an independent risk factor for developing ocular manifestations [54]. One idea behind this difference between age groups is that age may actually affect patient immunity.

One limitation of the present study is that we diagnosed keratoconjunctivitis sicca using only a subjective index, the OSDI questionnaire. Recently, ocular surface staining scores by the Oxford system [55], tear film breakup time, and the Schirmer-1 test scores were used as objective signs for diagnosing keratoconjunctivitis sicca. Another limitation of our study is its small population of AIDS patients not on HAART.

In conclusion, this study demonstrated that the introduction of HAART has changed the landscape of ocular presentations. The incidence of anterior segment and external ocular manifestations was higher than posterior segment manifestations, and the most common ocular manifestation in this study was retinal microvasculopathy, followed by keratoconjunctivitis sicca and conjunctival mirovasculopathy. Posterior segment manifestations were common in patients with $\mathrm{CD} 4+$ counts $<200$ cells $/ \mu \mathrm{L}$, while anterior segment manifestations were common in patients with CD4+ counts of 200 to 499 cells $/ \mu \mathrm{L}$. Age $>35$ years was also found to be an independent risk factor for developing ocular manifestations.

\section{Conflict of Interest}

No potential conflicts of interest relevant to this article was reported.

\section{Acknowledgements}

This work was supported by the Soonchunhyang University Research Fund.

\section{References}

1. Gottlieb MS, Schroff R, Schanker HM, et al. Pneumocystis carinii pneumonia and mucosal candidiasis in previously healthy homosexual men: evidence of a new acquired cel- lular immunodeficiency. N Engl J Med 1981;305:1425-31.

2. Jeng BH, Holland GN, Lowder CY, et al. Anterior segment and external ocular disorders associated with human immunodeficiency virus disease. Surv Ophthalmol 2007;52: 329-68.

3. Moraes HV Jr. Ocular manifestations of HIV/AIDS. Curr Opin Ophthalmol 2002;13:397-403.

4. Vrabec TR. Posterior segment manifestations of HIV/ AIDS. Surv Ophthalmol 2004;49:131-57.

5. Shah SU, Kerkar SP, Pazare AR. Evaluation of ocular manifestations and blindness in HIV/AIDS patients on HAART in a tertiary care hospital in western India. Br J Ophthalmol 2009;93:88-90.

6. Hodge WG, Seiff SR, Margolis TP. Ocular opportunistic infection incidences among patients who are HIV positive compared to patients who are HIV negative. Ophthalmology 1998;105:895-900.

7. Kestelyn PG, Cunningham ET Jr. HIV/AIDS and blindness. Bull World Health Organ 2001;79:208-13.

8. Lai TY, Wong RL, Luk FO, et al. Ophthalmic manifestations and risk factors for mortality of HIV patients in the post-highly active anti-retroviral therapy era. Clin Experiment Ophthalmol 2011;39:99-104.

9. Shuler JD, Engstrom RE Jr, Holland GN. External ocular disease and anterior segment disorders associated with AIDS. Int Ophthalmol Clin 1989;29:98-104.

10. Rodrigues ML, Rodrigues Mde L, Figueiredo JF, de Freitas JA. Ocular problems in Brazilian patients with AIDS before and in highly active antiretroviral therapy (HAART) era. Braz J Infect Dis 2007;11:199-202.

11. Goldberg DE, Smithen LM, Angelilli A, Freeman WR. HIV-associated retinopathy in the HAART era. Retina 2005;25:633-49.

12. Hogg RS, O'Shaughnessy MV, Gataric N, et al. Decline in deaths from AIDS due to new antiretrovirals. Lancet 1997;349:1294.

13. Schiffman RM, Christianson MD, Jacobsen G, et al. Reliability and validity of the Ocular Surface Disease Index. Arch Ophthalmol 2000;118:615-21.

14. Miller KL, Walt JG, Mink DR, et al. Minimal clinically important difference for the ocular surface disease index. Arch Ophthalmol 2010;128:94-101.

15. Acharya NR, Cunningham ET Jr. Corneal, anterior segment, and adnexal manifestations of human immunodeficiency virus. Int Ophthalmol Clin 1998;38:161-77.

16. Biswas J, Fogla R, Gopal L, et al. Current approaches to di- 
agnosis and management of ocular lesions in human immunodeficiency virus positive patients. Indian J Ophthalmol 2002;50:83-96.

17. Freeman WR, Lerner CW, Mines JA, et al. A prospective study of the ophthalmologic findings in the acquired immune deficiency syndrome. Am J Ophthalmol 1984;97:13342.

18. Henderly DE, Freeman WR, Smith RE, et al. Cytomegalovirus retinitis as the initial manifestation of the acquired immune deficiency syndrome. Am J Ophthalmol 1987;103(3 Pt 1):316-20.

19. Holland GN, Gottlieb MS, Yee RD, et al. Ocular disorders associated with a new severe acquired cellular immunodeficiency syndrome. Am J Ophthalmol 1982;93:393-402.

20. Jabs DA. Ocular manifestations of HIV infection. Trans Am Ophthalmol Soc 1995;93:623-83.

21. Ausayakhun S, Watananikorn S, Ittipunkul N, et al. Epidemiology of the ocular complications of HIV infection in Chiang Mai. J Med Assoc Thai 2003;86:399-406.

22. Chiou SH, Liu CY, Hsu WM, et al. Ophthalmic findings in patients with acquired immunodeficiency syndrome. $J \mathrm{Mi}$ crobiol Immunol Infect 2000;33:45-8.

23. Gharai S, Venkatesh P, Garg S, et al. Ophthalmic manifestations of HIV infections in India in the era of HAART: analysis of 100 consecutive patients evaluated at a tertiary eye care center in India. Ophthalmic Epidemiol 2008;15: 264-71.

24. Kim SJ, Park SJ, Yu HG, et al. Ocular manifestations of acquired immunodeficiency syndrome in Korea. $J$ Korean Med Sci 2012;27:542-6.

25. Lin YC, Yang CH, Lin CP, et al. Cytomegalovirus retinitis and immune recovery uveitis in AIDS patients treated with highly active antiretroviral therapy in Taiwanese. Ocul Immunol Inflamm 2008;16:83-7.

26. Miyamoto C, Yashiro S, Nagata Y, Nagataki S. Ocular complications in patients infected with human immunodeficiency virus seen at the Acquired Immunodeficiency Syndrome Clinical Center. Nihon Ganka Gakkai Zasshi 2001;105:483-7.

27. Pathai S, Deshpande A, Gilbert C, Lawn SD. Prevalence of HIV-associated ophthalmic disease among patients enrolling for antiretroviral treatment in India: a cross-sectional study. BMC Infect Dis 2009;9:158.

28. Uemura A, Yashiro S, Takeda N, Oka S. Ocular complications in patients with human immunodeficiency virus infection. Nihon Ganka Gakkai Zasshi 2006;110:698-702.
29. Wang J, You Q, Yang H, et al. Retinal findings in Chinese patients with HIV infection. Ophthalmic Res 2008;40:98100.

30. DeCarlo DK, Penner SL, Schamerloh RJ, Fullard RJ. Dry eye among males infected with the human immunodeficiency virus. J Am Optom Assoc 1995;66:533-8.

31. Lucca JA, Farris RL, Bielory L, Caputo AR. Keratoconjunctivitis sicca in male patients infected with human immunodeficiency virus type 1. Ophthalmology 1990;97:100810.

32. Lucca JA, Kung JS, Farris RL. Keratoconjunctivitis sicca in female patients infected with human immunodeficiency virus. CLAO J 1994;20:49-51.

33. Biswas J, Madhavan HN, Kumarasamy N, Solomon S. Blepharitis and lid ulcer as initial ocular manifestation in acquired immunodeficiency syndrome patients. Indian $J$ Ophthalmol 1997;45:233-4.

34. Friedlaender MH, Masi RJ, Osumoto M, et al. Ocular microbial flora in immunodeficient patients. Arch Ophthalmol 1980;98:1211-3.

35. Kahraman G, Krepler K, Franz C, et al. Seven years of HAART impact on ophthalmic management of HIV-infected patients. Ocul Immunol Inflamm 2005;13:213-8.

36. Teich SA. Conjunctival vascular changes in AIDS and AIDS-related complex. Am J Ophthalmol 1987;103(3 Pt 1):332-3.

37. Engstrom RE Jr, Holland GN, Hardy WD, Meiselman HJ. Hemorheologic abnormalities in patients with human immunodeficiency virus infection and ophthalmic microvasculopathy. Am J Ophthalmol 1990;109:153-61.

38. Geier SA, Klauss V, Goebel FD. Ocular microangiopathic syndrome in patients with acquired immunodeficiency syndrome and its relationship to alterations in cell adhesion and in blood flow. Ger J Ophthalmol 1994;3:414-21.

39. Ali R, Kim JY, Henderson BA. Adnexal and anterior segment manifestations of HIV/AIDS. Int Ophthalmol Clin 2007;47:15-32.

40. d'Arminio Monforte A, Mainini F, Testa L, et al. Predictors of cytomegalovirus disease, natural history and autopsy findings in a cohort of patients with AIDS. AIDS 1997; 11:517-24

41. Drew WL. Cytomegalovirus infection in patients with AIDS. Clin Infect Dis 1992;14:608-15.

42. Gallant JE, Moore RD, Richman DD, et al. Incidence and natural history of cytomegalovirus disease in patients with advanced human immunodeficiency virus disease treated 
with zidovudine. The Zidovudine Epidemiology Study Group. J Infect Dis 1992;166:1223-7.

43. Hoover DR, Saah AJ, Bacellar H, et al. Clinical manifestations of AIDS in the era of pneumocystis prophylaxis. Multicenter AIDS Cohort Study. N Engl J Med 1993;329:1922-6.

44. Palella FJ Jr, Delaney KM, Moorman AC, et al. Declining morbidity and mortality among patients with advanced human immunodeficiency virus infection. HIV Outpatient Study Investigators. N Engl J Med 1998;338:853-60.

45. Collier AC, Coombs RW, Schoenfeld DA, et al. Treatment of human immunodeficiency virus infection with saquinavir, zidovudine, and zalcitabine. AIDS Clinical Trials Group. N Engl J Med 1996;334:1011-7.

46. Hammer SM, Squires KE, Hughes MD, et al. A controlled trial of two nucleoside analogues plus indinavir in persons with human immunodeficiency virus infection and CD4 cell counts of 200 per cubic millimeter or less. AIDS Clinical Trials Group 320 Study Team. N Engl J Med 1997;337:725-33.

47. Robinson MR, Reed G, Csaky KG, et al. Immune-recovery uveitis in patients with cytomegalovirus retinitis taking highly active antiretroviral therapy. Am J Ophthalmol 2000; 130:49-56.

48. Karavellas MP, Lowder CY, Macdonald C, et al. Immune recovery vitritis associated with inactive cytomegalovirus retinitis: a new syndrome. Arch Ophthalmol 1998;116:169-75.

49. Kuppermann BD, Petty JG, Richman DD, et al. Correlation between CD4+ counts and prevalence of cytomegalovirus retinitis and human immunodeficiency virus-related noninfectious retinal vasculopathy in patients with acquired immunodeficiency syndrome. Am J Ophthalmol 1993;115:57582.

50. Geier SA, Libera S, Klauss V, Goebel FD. Sicca syndrome in patients infected with the human immunodeficiency virus. Ophthalmology 1995;102:1319-24.

51. Turner BJ, Hecht FM, Ismail RB. CD4+ T-lymphocyte measures in the treatment of individuals infected with human immunodeficiency virus type 1: a review for clinical practitioners. Arch Intern Med 1994;154:1561-73.

52. Ambiya V, Sagar A, Patyal S, Mohanty AP. Ocular manifestations in 321 male consecutive cases of human immunodeficiency virus infection/acquired immunodeficiency syndrome at an HIV-referral centre. Med J Armed Forces India 2012;68:214-21.

53. Ndoye NB, Sow PS, Ba EA, et al. Ocular manifestations of AIDS in Dakar. Dakar Med 1993;38:97-100.

54. Bekele S, Gelaw Y, Tessema F. Ocular manifestation of HIV/AIDS and correlation with CD4+ cells count among adult HIV/AIDS patients in Jimma town, Ethiopia: a cross sectional study. BMC Ophthalmol 2013;13:20.

55. Bron AJ, Evans VE, Smith JA. Grading of corneal and conjunctival staining in the context of other dry eye tests. Cornea 2003;22:640-50. 